RU Особенности организации синтаксического уровня рецензии (на материале русского и английского языков)

\author{
Зеленяева А. А.
}

\begin{abstract}
Аннотация. Цель исследования - выявить особенности организации синтаксического уровня рецензии как жанра на материале русскоязычных и англоязычных СМИ. Автор статьи проводит сопоставительный анализ основных синтаксических характеристик каждого из структурных разделов рецензии. Научная новизна состоит в установлении синтаксических особенностей текстов рассматриваемого жанра с точки зрения формального подхода. В результате доказано, что в рецензиях двух языков представлен широкий спектр разнообразных синтаксических конструкций. Выбор синтаксической конструкции находится в определенной зависимости от структурной части рецензии, в которой она употреблена.
\end{abstract}

\title{
Major Syntactic Characteristics of Review Organisation (Based on the Russian and English Languages)
}

\section{Zelenyaeva A. A.}

\begin{abstract}
The aim of the study is to identify the main syntactic characteristics in the organization of the review as a genre based on the material of the Russian-language and English-language media. The author of the article conducts a comparative analysis of the main syntactic characteristics of each structural section of the review. The scientific originality consists in addressing the syntactic level of texts of the genre under consideration from the point of view of the formal approach. As a result, it has been proved that the reviews of two languages represent a wide range of various syntactic constructions. The choice of a syntactic structure depends to a certain extent on the structural part of the review in which it is used.
\end{abstract}

\section{Введение}

Отличительной характеристикой информационного общества является производство информационного продукта. На данный момент ведущую роль среди всех видов средств массовой информации все более прочно занимают электронные источники. В сети современный человек может получить любой вид запрашиваемой информации, которая позволяет ему ориентироваться в окружающей действительности. Одним из видов подобной информации является рецензия, которая направляет выбор человека во всем разнообразии предлагаемых продуктов и в определенной степени может влиять на его предпочтения. Рассмотрение рецензии в лингвистике уже имеет определенную историю. Однако чаще всего лингвистов интересует рецензия как сам жанр текста (Набиева, 2010; Яворская, 2000) или оценочный потенциал рецензии и средства его реализации (Букина, 2020; Кашпар, 2018). Актуальность данного исследования обусловлена рассмотрением непосредственно синтаксического уровня рецензии, который раньше иногда затрагивался в работах, посвященных данному жанру, чаще всего в ракурсе стилистического потенциала рассматриваемого языкового уровня. Особый интерес изучение синтаксического уровня представляет в сопоставительном аспекте. Суммируя сопоставительные исследования различных лингвистов, посвященные жанру литературной критики начиная с XIX века, А. Г. Башкатова (2013) пишет о существовании двух разных парадигм в традиции составления рецензии: «...западные критики ориентировались, как правило, на художественные аспекты произведений и эстетический анализ текста; русские - на жизнь, на отображение жизни в литературе» (с. 15). Таким образом, нам представляется интересным посмотреть, есть ли различия в синтаксической организации рецензии на русском и английском языках, так как эти данные будут полезны при обучении студентов правильному прочтению рецензий на иностранном языке и составлению своих собственных текстов.

Для достижения поставленной цели необходимо решить следующие задачи: во-первых, создать сопоставимый корпус рецензий из русскоязычных и англоязычных источников; во-вторых, провести анализ синтаксического 
уровня отобранных текстов, учитывая структуру рецензии (для выявления лингвистических параметров рассматриваемых текстов была использована система RuLingva (https://rulingva.kpfu.ru/)), и, в-третьих, сравнить выделенные синтаксические характеристики рассматриваемого жанра в русском и английском языках. Для решения поставленных задач в работе был использован описательный метод с привлечением элементов количественного и сопоставительного анализов.

Теоретической базой исследования послужили научные труды, в которых рассмотрена рецензия как особый жанр публицистики (Башкатова, 2013; Земцова, 2006; Нерсесова, 2012), и исследования синтаксиса языка как языковой системы (Руднев, 1959; Нуруев, 2016; Ибрагимова, Ахметова, 2020).

Практическая значимость исследования заключается в том, что сопоставительный анализ рецензий дает возможность выделить отличительные особенности организации синтаксического уровня каждой из структурных составляющих текстов данного жанра в исследуемых языках. Полученные результаты могут быть использованы в курсе «Иностранный язык» по таким направлениям подготовки специалистов в рамках высшей школы, как: «Лингвистика», «Теория и методика преподавания иностранных языков и культур», «Переводоведение», «Журналистика».

\section{Основная часть}

Рецензия является вторичным текстом, так как представляет собой производный текст по отношению к произведению искусства (Букина, 2020, с. 40). В рамках данного исследования была рассмотрена критика продуктов духовной деятельности, художественная критика в соответствии с предложенной Т. Е. Нерсесовой предметнотематической типологией (2012). Другими словами, в наш корпус вошли книжные, театральные, музыкальные рецензии и кинорецензии (по 30 рецензий на каждом из рассматриваемых языков), которые были опубликованы в сентябре-ноябре 2021 года в таких изданиях, как «Российская газета» и The Guardian на их официальных сайтах (https://rg.ru/ и https://www.theguardian.com/international соответственно). Выбор данных газет был обусловлен тем, что они считаются качественной прессой с внушительным числом читателей, и тем, что в обеих газетах широко представлен раздел «Культура».

Несмотря на то, что в рамках проведенного исследования мы последовательно анализировали материал каждого из рассмотренных языков, нам кажется уместным представлять результаты исследования сразу на материале обоих языков, так как сама структура рецензии совпадает в двух рассмотренных языках.

Рецензия состоит из следующих частей: заголовок, лид (первый абзац) и основная часть. Так как данные части несут разную информационную и прагматическую нагрузку, их организация на синтаксическом уровне обладает существенными различиями. Опишем каждую из этих частей отдельно.

Цель заголовка - указать на рецензируемый продукт и дать ему наиболее сжатую характеристику. Во всех рассмотренных рецензиях авторы следуют четким принципам его построения. В 70\% русскоязычных рецензий заголовок обычно представлен одним полным простым предложением с четкой структурой: подлежащее, сказуемое и второстепенные члены предложения (чаще всего обстоятельство времени, места или дополнение (Большой театр представил две премьеры на камерной сцене.)). В 30\% проанализированных статей заголовок выражен простым односоставным безличным предложением, в котором на первое место вынесено обстоятельство места (В галерее Александра Шилова исполнили музыку по мотивам его живописи.). Количество слов в заголовке составляет 4-8 слов, относящихся к значимым частям речи.

Все рецензии на сайте газеты The Guardian имеют заголовки одной типовой структуры: сложное предложение, состоящее из двух простых с бессоюзной синтаксической связью и тире между ними: The Mad Women's Ball review - Mélanie Laurent's compelling melodrama. / Рецензия на «Бал безумных женщин» - убедительная мелодрама Мелани Лоран (здесь и далее перевод выполнен автором статьи. - А. 3.). В первом предложении обозначается жанр текста благодаря слову “review” и рецензируемый продукт; во втором -приводится краткое «представление» данного произведения. Первая часть заголовка во всех статьях выборки представляет собой простое именное предложение, вторая может быть простым именным предложением (Love Yourself Today review tearful celebration of Damien Deтpsey's тиsic. / Рецензия на Love Yourself Today - слезливое торжество музыки Дэмьена Демпси.) или простым предложением с двумя главными членами (The Boo Radleys review - boisterous comeback gives a glimpse of greatness. / Рещензия на The Boо Radleys - бурное возвращение дает представление о величии.). Количество значимых слов в заголовках английских рецензий составляет 6-10 слов.

Интересно отметить, что в рецензиях в заголовках могут встречаться прилагательные. Однако в русском языке прилагательные встречаются довольно редко (30\% от всех рассмотренных рецензий). Это в основном качественные прилагательные, описывающие характеристики объекта, но не дающие ему оценку (например, новый, музыкальный, экологический). В английских рецензиях прилагательные встречаются чаще (70\% рецензий). Кроме того, многие из них несут в себе определенную оценку (dramatic) или описывают эмоции (boisterous, piercingly sad). Taким образом, если цель заголовка в русскоязычной статье - исключительно информировать читателя о факте существования какого-либо продукта, то в англоязычной прессе уже заголовок носит оценочный характер.

Вторая часть рецензии - лид (первый абзац рецензии), целью которого является привлечь внимание читателя и в сжатой форме дать первую характеристику рецензируемому произведению. Во всех рассмотренных рецензиях данная часть структурно занимает один абзац. Более детальный анализ данной части позволил выделить существенные различия в составлении лида на рассматриваемых языках. 
Сначала обратимся к англоязычному лиду, так как он обладает более четкой структурой. Лид представляет собой одно предложение, в составе которого нами были зарегистрированы 1 или 2 грамматические основы. Это предложение обычно раскрывает тему рецензируемого события и дает ему первую общую оценку (Bеаиtifully shot documentary successfully explains the Dublin singer-songwriter's appeal by focusing on what his songs mean to fans. / Прекрасно снятый документальный фильм успешно объясняет привлекательность дублинского автораисполнителя, фокусируясь на значимости его песен для поклонников.). В основном синтаксическая структура предложений лида относительно четкая: подлежащее, сказуемое, несколько второстепенных членов. Основной осложняющей структурой являются однородные члены предложения (Stephan Helpert's doc highlights three white aid workers in DRC and asks who really benefits from their presence. / Документальный фильм Стефана Хельперта рассказывает о трех белых сотрудниках гуманитарных организаций в Конго и задается вопросом, кому на самом деле выгодно их присутствие.), которые позволяют в максимально сжатой форме подчеркнуть разнообразные аспекты рецензируемого продукта. Интересно отметить, что уже в тексте лида 89\% проанализированных рецензий были зафиксированы прилагательные, которые раскрывают отношение автора к рецензируемому продукту (cracking jokes; A compelling, cleverly inventive LP; this comforting, intimate album).

В отличие от англоязычного лида, лид русскоязычных рецензий не создается по четким правилам. Количество предложений в нем может варьироваться от 1 до 5-6. Некоторые предложения могут содержать в себе до 4-5 грамматических основ. Большинство предложений лида (98\%) являются распространенными. Они могут быть осложнены однородными членами предложения (Но гитарист изменил режим, подтянул здоровье и организовал собственный квартет Megadeth...), причастными оборотами (Часовой альбом, доступный на всех стриминговых площадках, состоит из 27 треков и организован просто...), вынесением на первое место обстоятельства времени (В понедельник, 13 сентября, Мастейну исполняется 60 лет и празднует эту дату он снова в хорошем настроении.) и т.д. Интересно отметить, что лид текста рецензии «Александринский театр открыл сезон спектаклем под проливным дождем в Пскове» представляет собой последовательность из 4 неполных распространенных предложений: Отмолить душу внезапно скончавшегося мужа, переодевшись в мужское платье и приняв его обличье... Пройти по следам духовный путь петербургской святой Ксении Блаженной... Успеть за ее внутренней молитвой, идущей от сердца со скоростью 12 метров в секунду, как шквалистый ветер... Дышать в такт спектаклю Валерия Фокина...

Отличительной особенностью лида рецензии на русском языке является использование односоставных предложений (Рецензия на фильм Кирилла Серебренникова «Петровы в гриппе» по роману Алексея Сальникова.), иногда даже нераспространенных (Неспроста.).

Таким образом, если в англоязычной статье лид имеет вполне четкую структуру и может реализовываться через ограниченное количество синтаксических конструкций, то при написании лида у русскоязычных авторов больше свободы: они могут использовать любые синтаксические конструкции в соответствии с поставленной прагматической задачей.

Теперь перейдем к рассмотрению основной части рецензии, где в полной мере раскрывается мнение автора о рецензируемом продукте. Именно эта часть рецензий на обоих языках является наиболее «неоднородной» с точки зрения синтаксического уровня.

Основная часть представляет собой текст из нескольких абзацев. Наиболее общие количественные характеристики данной части рецензии приводятся в Таблице 1. При подсчете количества слов в предложении учитывались только значимые части речи.

Таблица 1. Количественные характеристики основной части рещензии

\begin{tabular}{|l|l|c|c|}
\hline \multicolumn{2}{|c|}{ Параметры } & Русские рецензии & Английские рецензии \\
\hline \multirow{2}{*}{ Объем рецензии (количество слов) } & Максимальное & 985 слов & 927 слов \\
\cline { 2 - 4 } & Минимальное & 229 слов & 289 слов \\
\hline \multirow{2}{*}{ Количество абзацев } & Максимальное & 13 абзацев & 11 абзацев \\
\cline { 2 - 4 } & Минимальное & 5 абзацев & 3 абзаца \\
\hline \multirow{2}{*}{ Количество слов в одном предложении } & Максимальное & 35 слов & 47 слов \\
\cline { 2 - 4 } & Минимальное & 3 слова & 4 слова \\
\hline \multicolumn{2}{|l|}{ Наиболее часто встречающееся количество слов в предложении } & $16-29$ слов & $30-42$ слова \\
\hline
\end{tabular}

Интересно отметить, что соотношение простых и сложных предложений в рецензиях на рассматриваемых языках также различается. В русскоязычном материале доля простых предложений составила $46 \%$, сложных - 54\%. В англоязычных статьях в основной части рецензии нами было зарегистрировано преимущественное использование сложных предложений (83\%), которые могут содержать до 5-6 простых предложений в своем составе. Простые предложения в основной части рецензии скорее являются исключением и встречаются либо в начале абзаца (92\% случаев), либо как заключительное предложение абзаца или всей рецензии (8\% случаев) и не содержат более 8 слов. Если простое предложение открывает абзац (So who are the mad people here? / Так кто же здесь сумасшедшие?), то оно чаще всего имеет форму вопроса и помогает автору имитировать устную речь, «установить диалог» с читателем. Если мы обратимся к завершающим простым предложениям, то увидим, что подобное синтаксическое оформление предложений позволяет авторам привлечь внимание читателя к идеям, выраженным в них (Nothing hangs together. / Все разваливается.). В большинстве случаев резко повышается и оценочный потенциал всего высказывания. 
В основной части рецензии на двух рассматриваемых языках большая часть предложений являются осложненными. В русском языке наиболее часто востребованными синтаксическими конструкциями являются однородные члены предложения, причастные и деепричастные обороты, парцеллятивные конструкции. Интересно, что все эти конструкции могут встречаться в одном и том же сложном предложении, переплетаясь между собой: Маэстро Бедетти, 44-летний итальянский пианист и композитор, учившийся музыке в консерватории Antonio Buzzola, Национальной Академии Santa Cecilia и Accademia Musicale Chigiana, сочиняет симфоническую и хоровую музыку, пишет для театральных постановок...

В англоязычных рецензиях предложения такого типа чаще всего осложнены за счет Participle Construction, Detached Construction, Relative Clause, также однородных членов предложений и за счет вынесения различных дополнений на первое место в предложении: Back in 2011, the sudden ubiquity of Jessica Chastain - from small-screen blinkand-misses to big-screen "oh, her again" hits - meant that doors that had previously been closed were now opening, a relative embarrassment of riches for an actor breaking out in her 30s. / В 2011 году внезапная популярность Джессики Честейн от неудачных ролей на малом экране до «о, опять она» хитов на большом экране - означала, что двери, которые раньше были закрыты, теперь открываются, сомнительный успех для актера, начинающего карьеру в 30 лет.

Отличительной чертой русских рецензий можно считать большое количество предложений с обобщающим словом при однородных членах предложения (Тревожный звук оркестра, нервный, взвинченный монолог Маддалены о «зловещем и прекрасном» закате, тени, блуждающие по стенам, - это мрачная завязка спектакля, в котором...). В русскоязычных рецензиях нами были зарегистрированы обобщающие слова - в 27\% случаев предложений с однородными членами, в то время как в английском языке - только в 3\% случаев.

Кроме того, необходимо отметить, что в русской критике нами было зафиксировано большое количество употреблений предложений с прямой речью. Чаще всего они оформляются именно по правилам передачи прямой речи, а не цитирования (На репетициях не роптала: «Этот холод... Мне кажется, это еще недостаточный холод...»). Прямая речь может быть репликой из рецензируемого продукта («Почему все живут так, как будто это будет продолжаться вечно?» - рассуждает главная героиня, принимая решение делать...) или критическим комментарием одного из участников описываемого события (- Этот свет, идущий от полотен, от лиц их героев, чем-то напомнил мне итальянских классиков - Веронезе, Пармиджанино, - вспоминает Бедетти. - Вернувшись в Италию, я...). Примеры прямой речи были зарегистрированы в 37\% проанализированных русскоязычных рецензий. В английских рецензиях присутствие прямой речи является скорее исключением (6\% английских статей из корпуса).

Необходимо также подчеркнуть, что можно говорить о следующей тенденции, свойственной англоязычным рецензиям: чем рецензия короче, тем выше процентное содержание в ней простых предложений или сложных предложений с двумя простыми. В русском языке подобной зависимости синтаксической структуры от объема рецензии замечено не было.

\section{Заключение}

Суммируя приведенные выше факты, можно констатировать, что структура рецензий на сайтах рассмотренных газет как особого жанра духовной критики в русском и английском языках полностью совпадает: выделяются одни и те же части рецензии, которые выполняют одинаковые функции. При этом с точки зрения синтаксиса можно говорить о существенных различиях между отдельными частями русскоязычных и англоязычных рецензий. Англоязычные рецензии отличаются более традиционной синтаксической структурой: заголовок и лид характеризуются строгостью использования определенного набора синтаксических конструкций, не допускающей большого «креатива» со стороны автора. Основная часть англоязычной рецензии характеризуется разнообразием используемых синтаксических конструкций с большим процентом сложных, распространенных, осложненных предложений. В русскоязычных рецензиях сам жанр накладывает ограничения на синтаксическую организацию исключительно заголовка, а в лиде и в основной части рецензии авторы прибегают к использованию всего арсенала синтаксических средств языка, исходя из своей практики и общих прагматических установок.

Перспективы дальнейшего исследования проблемы мы видим в первую очередь в увеличении и разнообразии количества источников, привлекаемых к рассмотрению. Это в более полной мере будет отражать языковые характеристики рецензии на конкретном языке, а не в определенной степени «традиции» отдельного издательства или ее автора.

\section{Источники | References}

1. Башкатова А. Г. Литературная рецензия в контексте современных тенденций развития культуры: автореф. дисс. ... к. филол. н. М., 2013.

2. Букина Т. Г. Средства создания оценки в рецензии (на примере рецензии на фильм «Зеленая книга») // CHRONOS: мультидисциплинарные науки. 2020. № 11 (50).

3. Земцова Л. А. Искусствоведческая рецензия как жанр массово-информационного дискурса: автореф. дисс. ... к. филол. н. Волгоград, 2006.

4. Ибрагимова Ж., Ахметова А. Из теории трехуровневого подхода к синтаксису, формальный и семантический аспекты синтаксиса // Актуальные научные исследования в современном мире. 2020. № 9-4 (65). 
5. Кашпар М. С. Средства выражения оценки в аналитическом жанре рецензии (на материале рецензий Татьяны Москвиной в газете «Аргументы недели») // Рациональное и эмоциональное в русском языке: сб. тр. Международной научной конференции (г. Москва, 23-24 ноября 2018 г.). М., 2018.

6. Набиева Е. А. Оценочность в жанре рецензии: лингвистический и прагматический аспекты (на материале «Литературной газеты» и региональной парламентской газеты «Тюменские новости» постсоветского периода 1993-1995 и 2003-2005 гг.): автореф. дисс. ... к. филол. н. Тюмень, 2010.

7. Нерсесова Т. Е. Типы и жанры рецензирования в современных печатных СМИ: автореф. дисс. ... к. филол. н. M., 2012.

8. Нуруев Т. Э. Исследование осложненного предложения в общем языкознании и тюркологии // Филологические науки. Вопросы теории и практики. 2016. № 6-2 (60).

9. Руднев А. Г. Синтаксис осложненного предложения. М.: Учпедгиз, 1959.

10. Яворская С. М. Рецензия как тип текста (на материале англоязычной рецензии): автореф. дисс. ... к. филол. н. Львов, 2000.

\section{Информация об авторах | Author information}

RU Зеленяева Анастасия Александровна ${ }^{1}$, к. филол. н.

${ }^{1}$ Государственный музыкально-педагогический институт им. М. М. Ипполитова-Иванова, г. Москва

EN Zelenyaeva Anastasia Aleksandrovna ${ }^{1}, \mathrm{PhD}$

${ }^{1}$ The State Musical Pedagogical Institute named after M. M. Ippolitov-Ivanov, Moscow

${ }^{1}$ anaszel@mail.ru

\section{Информация о статье | About this article}

Дата поступления рукописи (received): 01.12.2021; опубликовано (published): 31.01.2022.

Ключевые слова (keywords): рецензия; структура; синтаксический уровень; предложение; review; structure; syntactic level; sentence. 